\title{
Explaining the Energy Efficiency Gap - Expected Utility Theory versus Cumulative Prospect Theory
}

by

Björn Häckel, Stefan Pfosser, Timm Tränkler 


\section{Häckel, Björn}

Research Center Finance \& Information Management, University of Augsburg Universitätsstr. 12, 86159 Augsburg

bjoern.haeckel@fim-rc.de

\section{Pfosser, Stefan}

Research Center Finance \& Information Management, University of Augsburg Universitätsstr. 12, 86159 Augsburg

stefan.pfosser@fim-rc.de

\section{Tränkler, Timm}

(corresponding author)

Research Center Finance \& Information Management, University of Augsburg Universitätsstr. 12, 86159 Augsburg timm.traenkler@fim-rc.de 


\title{
Explaining the Energy Efficiency Gap - Expected Utility
}

\section{Theory versus Cumulative Prospect Theory}

\begin{abstract}
Energy efficiency is one of the key factors in mitigating the impact of climate change and preserving non-renewable resources. Although environmental and economic justifications for energy efficiency investments are compelling, there is a gap between the observable and some notion of optimized energy consumption - the so-called energy efficiency gap. Behavioral biases in individual decision making have been resonated by environmental research to explain this gap. To analyze the influence of behavioral biases on decisions upon energy efficiency investments quantitatively, we compare Expected Utility Theory with Cumulative Prospect Theory. On basis of a real-world example, we illustrate how the extent of the gap is influenced by behavioral biases such as loss aversion, probability weighting and framing. Our findings indicate that Cumulative Prospect Theory offers possible explanations for many barriers discussed in literature. For example, the size of the gap rises with increased risk and investment costs. Because behavioral biases are systematic and pervasive, our insights constitute a valuable quantitative basis for environmental policy measures, such as customer-focused and quantitatively backed public awareness campaigns, financial incentives or energy savings insurances. In this vein, this paper may contribute to an accelerated adaption of energy efficiency measures by the broader public.
\end{abstract}

Keywords Energy Efficiency Investment; Energy Efficiency Gap; Cumulative Prospect Theory; Expected Utility Theory; Behavioral Barrier

\section{Introduction}

One of the key factors in mitigating the impact of climate change and preserving non-renewable resources is energy efficiency (EE). Recent sweeping environmental policy advances aim to drastically increase EE to combat global climate change. In its "Energy Roadmap 2050", the European Commission, by 2050, aims to reduce energy consumption of existing building stock by $80 \%$ relative to 2010 levels (European Commission 2011). Likewise, the U.S. Department of Energy has announced 
a massive program to promote EE (Department of Energy 2015). The environmental and economic justifications for investing in EE are compelling. According to Granade et al. (2009), energy consumption in the U.S. could be reduced as much as $23 \%$ by 2020 with cost-effective measures. Furthermore, most related theoretical work has stressed the economic cost-effectiveness of corresponding EE measures. However, and despite its widely asserted profitability, there seems to be an EE gap between the observable use of energy and some notion of optimized use (Rosenfeld et al. 1993; Brown et al. 1998). The EE gap, also called the EE paradox, is defined as the phenomenon that, although EE investments "seem to present clear economic and environmental advantages, the level of investment in them does not reach the levels which would correspond to such benefits" (Linares and Labandeira 2010, p.575-76).

\subsection{Explanations for the EE Gap}

Most of the explanations of this EE gap are based on standard neoclassical theory. In this vein, market failures, like environmental externalities, or imperfect information are identified as the main barriers to EE investments. From this point of view, decision-makers make rational decisions that maximize individual expected utility. In the context of EE choices, these decisions involve investments optimizing the result of the tradeoff between higher initial investment costs and increasing energy savings, depending on uncertain future energy expenses. Given perfect information and correct prices, it is assumed that the decision-maker perfectly and rationally processes information to maximize expected utility. However, those in behavioral economics propose that individuals are prone to a multitude of systematic biases that affect decisions in pervasive ways (Barberis 2013). The specifics of EE investments, such as long time horizons and high uncertainty about future savings, contribute to behavioral biases in individual decision-making. Many psychological biases are attributable to EE investments and are cited as good explanations for the EE gap (Greene 2011). Yet, while recent environmental policy literature often states the importance of behavioral biases, it mainly discusses these issues just qualitatively. For meaningful policy conclusions, however, a quantification of such behavioral effects might offer valuable information regarding the ecological and economic potential of 
possible measures. One approach to capture such behavioral effects in a quantitative model is the wellknown Prospect Theory (PT) of Kahneman and Tversky (1979).

\subsection{Prospect Theory as a quantitative model for explaining the EE gap}

Despite the call for the use of quantitative models that are not based on expected utility (non-expected utility models) for environmental policy analysis (Shaw and Woodward 2008), so far the application of PT to the case of EE investments is virtually absent. To describe the behavior of decision makers, and, in particular, to capture different systematic behavioral biases, PT mainly comprises four elements (Barberis 2013; Kahneman and Tversky 1979):

(1) Reference dependence: Decision-makers utility is described by reaction to changes in wealth (gains and losses) related to their current reference point rather than upon total wealth. The reference point, which divides gains from losses, is typically the status quo.

(2) Loss aversion: Decision-makers value the impact of losses bigger than that of gains.

(3) Diminishing sensitivity: Decision-makers are risk-averse in the domain of gains but risk seeking in the domain of losses. Thereby, with growing distance from the reference point, the impact of an outcome diminishes. This results in the well-known S-shaped value-function, which passes through the reference point and is concave over gains and convex over losses (cf. Figure 1).

(4) Probability weighting: Decision-makers weight the probabilities of the outcomes instead of using statistical probabilities. This reflects the empirical observation that decision-makers underweight average events (the center of the distribution), but overweight events with low probabilities (the tails of the distribution).

To analyze the influence of behavioral biases when deciding upon EE investments, we compare a rational Expected Utility Theory (EUT) decision-maker with a PT decision-maker who decides upon perceived value. As PT is mainly applicable to individual decision-making, the focus of this paper is on private decisions. Therefore, as a real-world application we analyze a prototypical EE investment in the weatherization of an owner-occupied residential building. This kind of investment bears significant potential for EE through improved insulation of the building envelope, while the costs for achieving 
the energy savings are relatively low (Jakob 2006). Nevertheless, the level of investment still seems to fall below the optimal level (Granade et al. 2009). In this context, we apply Cumulative Prospect Theory (CPT), which was introduced by Tversky and Kahneman (1992) as an advancement of the original PT to overcome the possible violation of first-order stochastic dominance.

While much research on the EE gap has stressed the importance of behavioral economics, to date empirical and quantitative theoretical work on PT and its elements in the context of EE investments is scarce. Therefore, the contribution of our paper is threefold: First, to the best of our knowledge, we are the first to implement all elements of CPT to quantitatively evaluate EE investments. In particular, we show how CPT can be applied to analyze EE investment decisions quantitatively based on a Net Present Value (NPV) approach. Second, we analyze if and to what extent, CPT can explain the EE gap, and the main parameters influencing it. Therefore, we use CPT to evaluate the distribution of possible NPVs of an EE investment as compared to EUT in order to deliver first quantitative evidence on the contribution of CPT to explaining the EE gap. Third, as our approach enables a thorough analysis and quantification of behavioral biases, we help to make behavioral biases addressable and correctible by environmental policy measures. Even though, we provide micro-level insights into the decision-making of an individual EE investor, the results from this paper support policy makers in generating incentives that accelerate the adoption of EE technologies on macro-level.

The remainder of this paper is organized as follows. In Section 2, we review research on the EE gap and barriers to investing in EE. Thereby, we put a focus on behavioral barriers. Section 3 includes descriptions of EUT and CPT in order to evaluate EE investments. This is followed by a discussion of specifics of EE investments, and how these are depicted within a NPV approach outlined in Section 4. The simulation analysis and its results are presented and discussed in Section 5. Finally, the conclusions and contributions to literature (and practice) are discussed in Section 6.

\section{The Energy Efficiency Gap}

In a very general form, Jaffe and Stavins (1994a, p.804) refer to the EE gap as "the paradox of gradual diffusion of apparently cost-effective energy-efficiency technologies”. Brown (2001, p.1198) defines 
the EE gap as "the difference between the actual level of investment in energy efficiency and the higher level that would be cost-beneficial from the consumer's (i.e., the individual's or firm's) point of view". Thus, in our context, we define the EE gap as the difference between observable investments in EE and a cost-effective level of EE investments that would be optimal from the perspective of a EUT decision-maker. Estimates for the size of the EE gap are wide ranging, but there is substantial empirical evidence for its existence. There are three streams in literature that indicate the existence of the EE gap based on different approaches: (1) macro-level engineering-economic studies (see e.g.: Brown et al. 1998; Granade et al. 2009; Rosenfeld et al. 1993). The basic approach in such studies is to calculate the NPV of possible EE measures given assumed capital costs, energy prices, investment horizons, and discount rates (Allcott and Greenstone 2012). (2) Case studies for specific products and technologies, which show that consumers and firms often choose not to invest in highly cost-effective EE measures (DeCanio and Watkins 1998; Gates 1983; Koomey and Sanstad 1994; Koomey et al. 1996; Meier and Whittier 1983). And (3) a large part of the evidence on the EE gap is based on analyses of implicit discount rates. Numerous studies report the observation that consumers use high implicit discount rates in making EE investment decisions (Dubin and McFadden 1984; Gately 1980; Hausman 1979; Min et al. 2014; Ruderman et al. 1987). However, sometimes the existence of the EE gap is viewed skeptically. For example, Allcott and Greenstone (2012) state that the EE gap is possibly only in the range of about 1 to $2 \%$ of energy use. Nevertheless, the majority of authors indicate that energy markets are full of barriers that could explain the EE gap.

\subsection{Barriers to EE investments}

Generally, barriers to EE investments represent factors that limit the diffusion of cost-effective EE measures (Vine et al. 2003). There are two main kinds of barriers to EE investments: (1) structural barriers and (2) behavioral barriers (Brown 2001; Hirst and Brown 1990; Shogren and Taylor 2008; Weber 1997). 


\subsubsection{Structural Barriers}

Structural barriers "result from the actions of many public- and private-sector organizations and are primarily beyond the control of the individual end-user" (Hirst and Brown 1990, p. 269). Literature distinguishes between market-failures and non-market failures.

Market failures occur when there is a deviation from the way perfect markets operate (Brown 2001). Commonly reported market failures are associated with externalities (Brown 2001; Gillingham et al. 2009; Jaffe et al. 2004), imperfect information (Allcott and Greenstone 2012; Howarth and Andersson 1993; Linares and Labandeira 2010), innovation market failures (Coltrane et al. 1986; Jaffe and Stavins 1994b;) and imperfect capital markets (Blumstein et al. 1980; Brown 2001; Gillingham et al. 2009).

Non-market failures refer to obstacles that explain why observed behavior is indeed optimal from the point of view of individual energy users (Brown 2001; Hirst and Brown 1990; Jaffe and Stavins 1994a). Its main point is the riskiness of EE investments (Hasset and Metcalf 1993; Metcalf 1994; van Soest and Bulte 2001) and barriers within institutions and organizations (Brown 2001; DeCanio 1993; De Groot 2001; Hirst and Brown 1990; Lovins 1992; Weber 1997).

Structural barriers and environmental policies derived predominantly from market-failures are usually based on a rational human actor in the sense of neoclassical theory (Gintis 2000). This presupposes that consumers and firms act in their self-interest, based on full information and rational calculus of cost, benefits, and risk to maximize expected utility. Despite its preeminence in economic models, the rationality hypothesis is often blamed for being an inadequate representation of actual human behavior. Many of the market and non-market failures to EE investments can also be traced back to individual decision-making that is prone to behavioral barriers (Shogren and Taylor 2008; Stern 2011; Wilson and Dowlabati 2007). 


\subsubsection{Behavioral Barriers}

Generally, behaviors with regards to energy conservation can be separated into efficiency and curtailment behaviors (Barr et al. 2005; Gardner and Stern 2002). Curtailment behaviors comprise repetitive 'habitual' behaviors in the context of energy usage, such as lowering thermostat settings. Efficiency behaviors relate to a single decision about the investment in an EE measure, also called 'technology choices'. Much of the existing empirical research has focused on curtailment behaviors (e.g., Abrahamse 2005). For instance, more recently, Allcott and Rogers (2014) examined a program to induce energy conservation by providing information, financial incentives as well as social comparison on basis of home energy reports. Empirical research on efficiency behavior is mainly focused on socio-economic analysis of purchasers of EE measures (e.g., Barr et al. 2005; Gaspar and Antunes 2011, Sütterlin et al. 2011). For owners of detached houses in Sweden, Nair et al. (2010) introduced several determinants, which they categorize into contextual factors and personal factors. ${ }^{1}$ Further, empirical research on efficiency behavior often analyses the influence of ex ante provision of information to potential investors in EE measures. For example, Fowlie et al. (2015) found high nonmonetary costs related to information acquisition. However, in this paper, we focus on behavioral barriers to EE that affect investment decisions even in case of perfect information. Thus, we start from a decision-maker able to observe and aggregate future outcomes, but failing to rationally process this information due to behavioral barriers.

Behavioral barriers imply that a decision-maker fails to behave as predicted by EUT (Stern 2011). The existence of behavioral economics has been substantiated by evidence that decision-makers are not perfectly rational. Even if they are given perfect information, they often systematically deviate from neoclassic economic assumptions of rationality (Kahneman and Tversky 1979). There exist persistent biases in individual decision-making that result in behavior not consistent with such rationality assumptions (Camerer and Loewenstein 2004; DellaVigna 2009).

\footnotetext{
${ }^{1}$ In Nair et al. (2010) contextual factors include homeownership, building age, need for thermal comfort, previous investments in EE, perceived energy costs and geographical location. Personal factors include education, income, age, gender, (technical) skill, awareness about EE measures and attitude.
} 
In energy literature, a wide range of research has demonstrated that assumptions of economic rationality regarding the behavior of energy users, and their investment decisions, are fundamentally flawed (Frederiks et al. 2015; Gillingham and Palmer 2014; Gintis 2000; Shogren and Taylor 2008; Stern 2011). Even having perfect information, decision-makers may not be able or motivated to make the complex calculus required to take the best decision. For instance, Kempton and Montgomery (1982) showed that energy consumers systematically deviate from cost minimizing behavior even when motivated to make careful decisions. Thus, early on, energy experts promoted the study of the social and psychological aspects of energy use as well as the psychological barriers to EE investments (Coltrane et al. 1986; Stern and Aronson 1984). Knetsch (1997, p.209) argued that "in view of the evidence, the seemingly quite deliberate avoidance of any accounting of these (behavioral) findings in the design of environmental policy or in debates over environmental values, does not appear to be the most productive means to improvement”. Further, Gintis (2000) asserted that individual decisionmaking systematically violates prevailing axioms of decision theory in the context of environmental policies. In particular, individuals are prone to the status quo bias, and exhibit time inconsistent preferences with regards to the evaluation of future costs and benefits ${ }^{2}$. Wilson and Dowlabati (2007) reviewed models of decision making in the residential energy context. As examples of irrational choice, they analyzed time inconsistency, framing, reference dependence, and bounded rationality. They concluded that the key findings of behavioral economics are observable in the real world. Gowdy (2008, p.632) "takes the position that so-called behavioral "anomalies" are central to human decision-making and, therefore, should be the starting point for effective economic policies". Frederiks et al. (2015), Pollitt and Shaorshadze (2013), Shogren and Taylor (2008), and Stern (2011) provided exhaustive summaries on the contributions of psychology to the understanding of human behaviors that drive climate change and human reactions to EE technologies. They concluded that psychological

\footnotetext{
${ }^{2}$ While time inconsistent preferences constitute an important insight into human decision making (see e.g.: Frederick et al. 2002, Laibson 1997), in this paper we assume a decision maker exhibiting time consistent preferences modelled with a NPV approach (also see Section 4). We do so for two reasons: First, our approach is based on the so-called method of risk analysis, which was underpinned by a decision-theoretical point of view in Bamberg et al. 2006. Accordingly, in a first step, periodical cash flows are aggregated to NPVs preference-free. Then, these NPVs are evaluated preference-based using a specific utility function. Second, we exclusively analyze the effects of all CPT elements as compared to EUT. Considering additional elements not covered by CPT, such as time inconsistency, may distort our findings and impede the analyses.
} 
factors are important determinants of EE related behaviors and "also influence the acceptance and implementation of public policies to limit climate change and the adoption of low-carbon energy technologies" (Stern 2011, p.311). Some authors also presented evidence on how behavioral failures might cause underinvestments in EE and thus cause the EE gap. For instance, Masini and Menichetti (2012) developed and tested a conceptual model that examined the behavioral factors affecting financial investment decisions in renewable energy technologies.

So far, we can conclude that previous literature has provided substantial evidence underlining that EUT should not be the only model to guide environmental decision-making. Despite this evidence, incorporation of non-expected utility models into the environmental economics literature has been relatively slow (Shaw and Woodward 2008). One of the best-known models of non-expected utility is PT (Barberis 2013). Kahneman and Tversky (1979) introduced a critique of EUT and developed an alternative model called PT, which is based on empirical (psychological) evidence and describes how decision-makers choose between a set of risky alternatives. In the literature on behavioral environmental economics, PT and its elements are widely cited as possible explanation for the EE gap (e.g., Gintis 2000; Gowdy 2008; Shogren and Taylor 2008; Stern 2011; Wilson and Dowlatabadi 2007). However, it is striking that, to the best of our knowledge, there is almost no research that aims to explain the EE gap by employing PT quantitatively or empirically. One exception is Mayer (1995) who empirically examined consumer rationality as compared to PT for electricity conservation. His findings support "the efficacy of prospect theory over utility maximization for consumer investment in electricity saving equipment" (Mayer 1995, p.109). However, Mayer only provided indirect evidence for the EE gap and did not investigate all elements of PT. Moreover, Greene (2011) applied certain elements of PT in a quantitative model to account for uncertainty and loss aversion. His model was used to examine the influence of uncertainty and loss aversion in the application scenario of increased fuel economy of new passenger cars. The author concluded that the examined implementation of PT "can explain the observed tendency for markets to undervalue energy efficiency improvements to new equipment relative to their expected value" (Greene 2011, p.616). However, the model did not incorporate all elements of PT (such as probability weighting). Thus, the aim of this study is to explain the EE gap by comparing an EE investment decision based on EUT with respect to CPT, depicting 
both rational decision-makers and decision-makers that decide upon perceived value. By means of such an explicit calculation, it is possible to draw quantifiable conclusions on the influence of behavioral barriers to the EE gap. This enables effective, consumer-focused policy making to improve EE. Therefore, in the next section, we will compare EUT with CPT regarding the evaluation of EE investments.

\section{Evaluation of EE Investments}

Standard neoclassical theory is based on the assumption that decision-makers behave rationally and make investment decisions that maximize their expected utility. Accordingly, EUT is a normative theory and investigates how decisions under risk should be made rationally. ${ }^{3}$ With decisions under risk, a formal representation of the decision problem is possible:

$$
E U T=\sum_{i=1}^{n} p\left(x_{i}\right) \cdot u\left(\varphi_{i}\right)
$$

where $n$ is the number of outcomes $x_{i}, p\left(x_{i}\right)$ is the objective probability of outcome $x_{i}$ and $u\left(\varphi_{i}\right)=$ $u\left(\varphi_{o}+x_{i}\right)$ is the individual utility of total wealth $\varphi_{i}$, which is the initial wealth $\varphi_{0}$ plus outcome $x_{i}{ }^{4}$ When the resulting EUT value is larger than initial utility $u\left(\varphi_{0}\right)$ then the investment is utility enhancing and should be executed.

In our analysis, however, we assume an investor, who decides upon the perceived value of an EE investment. As described above, PT is appropriate for evaluating an EE investment, because it resembles a decision of high uncertainty concerning costs, savings, and lifetime that gives rise to a number of behavioral biases. Furthermore, PT was designed for individual decision-making and is not quite applicable to company-level decision-making (Shogren and Taylor 2008). ${ }^{5}$ Thus, we will next

\footnotetext{
${ }^{3}$ EUT is based on three main principles: (1) the overall expected utility of a choice is the expected utility of the distribution of possible outcomes. (2) It exists a utility function $u()$ that represents the risk profile of an investor and can be used to value uncertain future outcomes $x_{i}$. (3) A choice is acceptable if it adds utility to the existing assets. ${ }^{4}$ In a more general form Expected Utility is defined as $E[u(\tilde{X})]$, where $\tilde{X}$ is a random variable. When $\tilde{X}$ is discretely distributed, Eq. (1) can be applied to compute the value of Expected Utility.

${ }^{5}$ The decisions of corporate managers on EE investments are (e.g., because of their high investment volume) usually preceded by intense discussions in several committees. PT may not be applicable to this comparatively rational organizational decision-making process. However, it may be applicable in a corporate context when corporate governance mechanisms are weak (Wen 2010) or if the contextual factors of the organization are considered (Shimizu 2007).
} 
analyze an individual PT decision-maker who evaluates an EE investment exhibiting reference dependence, loss aversion, diminishing sensitivity and probability weighting (see Section 1.2).

To capture the properties described above when evaluating a stochastic outcome $\Delta x_{i}$, Kahneman and Tversky (1979) suggested a value function $v()$ and a weighting function $w()$ that transform the outcomes and the probabilities compared to EUT. The first three elements described in Section 1.2, concerning a single outcome $\Delta x_{i}$, are implemented in the so-called value function:

$$
v\left(\Delta x_{i}\right)=\left\{\begin{array}{ll}
\left(\Delta x_{i}\right)^{\alpha} & \Delta x_{i} \geq 0 \\
-\lambda \cdot\left(-\Delta x_{i}\right)^{\beta} & \Delta x_{i}<0
\end{array},\right.
$$

with $\alpha=\beta=0.88$ being the weighting-factors that determine the curvature for the positive $(\alpha)$ and negative domain $(\beta)$, as originally specified in Kahneman and Tversky (1979). The parameter $\lambda=$ 2.25 captures loss aversion, expressing that decision-makers consider losses more than twice as important as gains. Figure 1 schematically illustrates the value function. The difference in the valuation of losses and gains becomes obvious at the origin of the function, which is the reference point.

(Enter Figure 1 here)

Figure 1: A hypothetical value function according to Kahneman and Tversky (1979).

However, the value function alone insufficiently describes human value perception. Decision behaviors such as buying insurance contracts (risk-averse loss perception) and gambling (risk-seeking gain valuation) contradict the results of the value function. Thus, instead of weighting the subjective values according to Eq. (2) with their objective probabilities, Tversky and Kahneman (1992) introduced the probability weighting function:

$$
w\left(p\left(\Delta x_{i}\right)\right)= \begin{cases}\frac{p\left(\Delta x_{i}\right)^{\gamma}}{\left(p\left(\Delta x_{i}\right)^{\gamma}+\left(1-p\left(\Delta x_{i}\right)\right)^{\gamma}\right)^{1 / \gamma}} & \text { for } \Delta x_{i} \geq 0 \\ \frac{p\left(\Delta x_{i}\right)^{\delta}}{\left(p\left(\Delta x_{i}\right)^{\delta}+\left(1-p\left(\Delta x_{i}\right)\right)^{\delta}\right)^{1 / \delta}} & \text { for } \Delta x_{i}<0\end{cases}
$$

The weighting function rescales objective probabilities $p\left(\Delta x_{i}\right)$ to perceived probabilities $w\left(p\left(\Delta x_{i}\right)\right)$ consistent with the concept of diminishing sensitivity. Thereby, $\gamma=0.61$ and $\delta=0.69$ are the factors that distinguish between the domain of gains and losses, and mainly control curvature. A multitude of 
studies have validated this functional form (e.g., Gonzalez and Wu 1999; Lattimore et al. 1992). ${ }^{6}$ However, because first-order stochastic dominance is potentially violated in the original PT, implying that a prospect might be evaluated superior although it yields an inferior outcome with certainty, an advancement was suggested by Tversky and Kahneman (1992). While single probabilities $p\left(\Delta x_{i}\right)$ are weighted in the original PT, cumulative probabilities are weighted in CPT. After cumulative probabilities have been weighted according to Eq. (3), the differences in neighboring probability weightings are computed to derive the decision weight $\pi_{i}$ for each outcome:

$$
\pi_{i}= \begin{cases}w\left(p\left(\Delta x_{i}\right)+\cdots+p\left(\Delta x_{n}\right)\right)-w\left(p\left(\Delta x_{i+1}\right)+\cdots+p\left(\Delta x_{n}\right)\right) & \text { for } \Delta x_{i} \geq 0 \\ w\left(p\left(\Delta x_{1}\right)+\cdots+p\left(\Delta x_{i}\right)\right)-w\left(p\left(\Delta x_{1}\right)+\cdots+p\left(\Delta x_{i-1}\right)\right) & \text { for } \Delta x_{i}<0\end{cases}
$$

where all outcomes $\Delta x_{i}$ are sorted in ascending order and $p\left(\Delta x_{i}\right)$ is the objective probability of the i-th outcome. Furthermore, it is valid for $\Delta x_{i}<0: 2 \leq i \leq k$ and for $\Delta x_{i} \geq 0: k+1 \leq i \leq n-1$, where $k$ is the number of negative outcomes. Following Tversky and Kahneman (1992), the decision weight related to a positive outcome $\left(\Delta x_{i} \geq 0\right)$ is the difference between the weighted cumulative probabilities of the events "the outcome is at least as good as $\Delta x_{i}$ " and "the outcome is strictly better than $\Delta x_{i}$ ". Correspondingly, the decision weight related to a negative outcome $\left(\Delta x_{i}<0\right)$ is the difference between the weighted cumulative probabilities of the events "the outcome is at least as bad as $\Delta x_{i}$ " and "the outcome is strictly worse than $\Delta x_{i}$ " (Tversky and Kahneman 1992, p.301). Finally, given the decision weights $\pi_{i}$ and the value weights $v\left(\Delta x_{i}\right)$, the CPT value of an EE investment is calculated as:

$$
C P T=\sum_{i=1}^{n} \pi_{i} \cdot v\left(\Delta \mathrm{x}_{i}\right)
$$

where $n$ is the number of possible outcomes. This results in the final CPT value, which is the perceived value of the distribution of outcomes that results from the EE investment for the individual

\footnotetext{
${ }^{6}$ However, there is also some literature that discussed shortcomings of the single-parameter probability weighting function (e.g., Ingersoll 2008). For example, Dichtl and Drobetz (2011) applied the probability weighting function suggested by Lattimore et al. (1992) that includes an additional parameter for elevation.
} 
decision-maker. Similar to EUT, a value greater than zero results in a favorable decision towards the EE investment. However, the CPT value may not be mistaken for a monetary value.

Although PT focuses on one-period outcomes rather than on long-term investment decisions, the functional form of the perceived value is not restricted to one-period outcomes (e.g., Camerer and Ho 1994; De Giorgi and Hens 2006; Fennema and Wakker 1997; Wakker 1989). However, the value of a long-term investment requires consideration of the status quo, aggregation of future outcomes, and consideration of the time value of money. We will consider those issues in the next section by introducing a multi-period NPV approach considering the status quo of the decision-maker. Thus, in the following, the outcome $\Delta x_{i}$ previously inserted in the value function will be replaced with an outcome for the NPV of the EE investment.

\section{NPV Approach to Model EE Investments}

An EE investment for an individual decision-maker is comparable to any other investment in real assets, because it reflects an initial financial expenditure followed by a subsequent, usually uncertain payoff (Sutherland 1991).

We apply standard NPV analysis and extend the method by incorporating risk and risk-preferences through valuation based on EUT and CPT. Standard NPV analysis is based on time consistent preferences modelled by exponential discounting. However, it is often stressed that human preferences are dynamically time inconsistent by behavioral economics in general (Frederick et al. 2002; Laibson 1997; Loewenstein and Thaler 1989; Thaler 1981) and for investments in EE in particular (Frederiks 2015; Gillingham and Palmer 2014; Gintis 2000; Wilson and Dowlabati 2007). Such time inconsistent preferences are formally modelled by hyperbolic or quasi-hyperbolic discount functions (Laibson 1997). However, as mentioned earlier, in this paper we exclusively focus on the comparison of EUT with CPT assuming intertemporal choice based on time consistent preferences. Considering additional elements not covered by CPT, such as time inconsistency, may distort our findings and impede the analyses. 
Additionally, NPV analysis is the most commonly used investment evaluation method applied in the EE literature (see e.g.: Adahl and Harvey 2007, Amstalden et al. 2007, Clinch and Healy 2001, Johnson 1994, Morrissey et al. 2013, Rickard 1998). In line with these works, we also apply NPV analysis to determine whether the present value of future energy savings surpasses the initial investment costs of the EE investment. The general form of the NPV calculation is:

$$
N P V=-I_{0}+\sum_{t=1}^{T} \frac{C F_{t}}{(1+r)^{t}}
$$

where $I_{0}$ is the initial investment cost of the EE investment at the time of decision $t=0$. The time horizon $T$ is usually set equal to the lifetime of the EE investment, the customer's expected useful life of the EE investment, or a subjective payback period of the EE investment (Thompson 1997). The time value of money is considered by discounting with the (risk-free) interest rate $r$. The cash flow $C F_{t}$ with $t \in\{1, \ldots, T\}$ includes the income in period $t$ that results from the EE investment during its time horizon $T$. Income in this setting is the cash flow from future energy savings that results from the EE investment each period. To determine the savings of period $t$, we use the following calculation:

$$
C F_{t}=P_{t} \cdot F_{c} \cdot \varepsilon \cdot M+U C B_{t} .
$$

Where $P_{t}$ is the stochastic price per unit of energy (e.g., kWh) for period $t . F_{c}$ depicts the current consumption of units of energy and $\varepsilon$ is the energy savings. If the EE investment results in $20 \%$ savings in energy, then it holds $\varepsilon=0.2$. Furthermore, the usage rate $M$ accounts for an increase or decrease in energy use that is triggered by the Rebound Effect, and is an implicit function of energy prices (Allcott and Greenstone 2012). The unobservable costs and benefits $U C B_{t}$ comprise items of expenditure and co-benefits in period $t$ that are not directly observable or hard to measure. For instance, increased thermal insulation may increase well-being and health, but the identification and quantification of $U C B_{t}$ are subject to considerable methodological issues (e.g., Clinch and Healy 2001). We also do not account for costs of financing, such as interest rate payments; thus, we assume full equity financing. 
However, investments typically do not provide fixed future periodical cash flows. Future cash flows rather depend on risky future developments (Johnson 1994) and thus, the NPV of an investment is also risky. Risk in our model is primarily associated with uncertainty about future fuel prices $P_{t}$, because the development of energy price paths cannot be predicted. Consequently, only the periodical distribution or possible range of the EE investment's cash flows can be determined (Johnson 1994). Thus, the investor has to evaluate the risk inherent in the resulting distribution of possible NPVs.

\section{Simulation Analysis}

In the subsequent sections, the introduced decision framework is applied to the case of energy-efficient refurbishment of private homes in the German market. For this analysis, first, we utilize information about energy consumption, EE potential, and investment costs, mostly obtained from a comprehensive study by the Institute for Housing and Environment (Enseling et al. 2013). ${ }^{7}$ Second, we simulate future energy prices with help of Monte-Carlo simulations in order to achieve a realistic representation of possible future real world prices (cf. Section 5.1). Third, we calculate resulting cash flows and the distribution of possible NPVs based on the future energy prices (cf. Section 5.2). Fourth, we apply the EUT and CPT framework described in Section 3 to evaluate the resulting NPVs (cf. Section 5.3). Finally, we compare and analyze the evaluation results (cf. Section 5.4).

\section{(Enter Figure 2 here)}

Figure 2: Approach for the analysis.

For our analysis, we refer to a model single-family detached house based on the German building typology (c.f. Table 1). This kind of house resembles a large portion of the German building stock (DENA 2012) and has great potential for EE measures because of the low energy standards at the time of construction. It is assumed that the considered building is in possession of the owner-occupier and will not be sold at the end of the time horizon T. We start our analysis by running Monte Carlo simulations of domestic fuel oil prices.

7 The "Institut Wohnen und Umwelt", the Institute for Housing and Environment, is a non-profit research institute of the State of Hesse and Darmstadt. Its research areas are housing, energy, and integrated sustainable development. 
(Enter Table 1 here)

Table 1: Model house's main specifications based on Enseling et al. (2013).

\subsection{Monte-Carlo Simulations}

As described in Section 4, the price of energy is one of the most relevant sources of uncertainty for EE investments (Diederen et al. 2003; Greene 2011; Hassett and Metcalf 1993). Thus, in a first step, we assume the domestic fuel oil price $P_{t}$ to be the source of risk. However, by varying the initial parameters of the EE investment (e.g., the investment costs $I_{0}$ and savings $\varepsilon$ ) a thorough analysis of further sources of risk is feasible. In the analysis at hand, the price of domestic fuel oil follows a geometric Brownian motion (GBM). This process has the desirable feature that forecast uncertainty increases with forecast horizon, and that extended periods of low and high energy-costs are observable. When modeling energy-price developments in such a way, there are two important parameters: (1) the long-term trend $\mu$ and (2) the degree of randomness around this trend $\sigma$. In formal terms, we model the GBM of $P_{t}$ as:

$$
\delta P_{t}=\mu P_{t} d t+\sigma P_{t} d z,
$$

where $d z$ is the increment to a Wiener process that describes the evolution of a standardized normally distributed variable with mean zero and unit variance. Thus, energy costs are rising linearly at trend rate $\mu$, but exhibit substantial randomness around the trend. The parameter $\sigma$ determines the degree of randomness and can be interpreted as the volatility of the energy price. We generate prices on a yearly evaluation period because many private investors evaluate their investments on a yearly basis (Benartzi and Thaler 1995) and energy costs are often calculated on an annual basis. Thus, $d t=1$ resembles a single yearly increment. The stochastic process for domestic fuel price as depicted in Eq. (8) is a very common way to model commodity and energy prices and is widely used in EE investment literature (e.g., Ansar and Sparks 2009; Diederen et al. 2003; Hassett and Metcalf 1993).

Using the stochastic process in Eq. (8), we simulate 25 years of energy prices. To derive the full distribution of domestic fuel oil prices, we perform 10,000 simulation runs per year. The initial energy price per $\mathrm{kWh}\left(P_{0}\right)$, the long-term trend $(\mu)$, and volatility $(\sigma)$, are specified using data from Enseling 
et al. (2013) that estimates the values from historical data and official studies. Thus, initially, we set the domestic fuel oil price $P_{0}=0.085 € / k W h$, long-term price trend $\mu=4.8 \%$ and price volatility $\sigma=20 \%$. Later, the parameters are varied to evaluate their influence on the EE investment decision.

The simulated energy price paths provide the basis for the calculation of the cash flows $C F_{t}$ and consequently the $N P V_{i}$. To obtain the $N P V_{i}$ for each price path $i=1$ to 10,000 with Eq. (6), the cash flows for all periods were computed with Eq. (7). Consequently, we derive the full distribution of NPVs of the EE investment.

\subsection{Calculation of NPVs}

Enseling et al. (2013) distinguish between maintenance measures (such as refurbishment of the exterior wall) and EE-related measures (such as the thermal insulation of the building envelope).

Usually such measures are carried out together. As this study focuses on EE investment decisions, the analysis only incorporates the costs and savings of the investment in EE related measures.

Based on the data of Enseling et al. (2013) which provided investment costs per square meter to achieve German energy standards ${ }^{8}$, we derived investment costs per square meter net dwelling area.

These comprise the costs of all energetic measures, which summed up to $31,133 €$, when looking at the EE investment alone. ${ }^{9}$ However, these are only the investment costs $I_{0}$ for the baseline scenario. Later, a range of $10,000 €$ to $60,000 €$ will be analyzed. The energy savings $\varepsilon$ that result from both, maintenance and EE investments, amount to about $65 \%$. Obviously, this level of energy savings $\varepsilon$ is too high when analyzing the savings of the EE investment alone, because it includes effects from maintenance measures as well. ${ }^{10}$ To address this issue and enable analyses of various possible settings, in the further analysis we will vary $\varepsilon$ in a broad range from $5 \%$ to $80 \%$, but assume that it is constant

\footnotetext{
${ }^{8}$ In particular, we consider as our baseline scenario an EE investment to achieve the KfW Efficiency House 100 standard, established by the German government-owned promotional bank KfW. This housing category conforms to the national energy standards laid out in the Energy Conservation Ordinance of 2007 (Energieeinsparverordnung/ EnEV) that set limits to energy consumption and heat loss values for new buildings. The KfW promotes refurbishment of houses and, for example, the Efficiency House 100 may not exceed the values specified in EnEV 2007 by $100 \%$. ${ }^{9}$ For reasons of comparability and simplicity, we used prices for 2013 as in Enseling et al. (2013). ${ }^{10}$ For example, the study by Enseling et al. (2013) assumed that the costs for exchanging the central heating were accounted for maintenance costs, because it would have needed to be replaced anyway.
} 
over time (i.e., there is no stochasticity related to the energy savings obtained by the EE investment). Thus, to cover a broad variety of possible constellations, we analyzed combinations of investment costs $I_{0}$ ranging from $10,000-60,000 €$ and energy savings ranging from 5-80\%. Table 2 summarizes the inputs to calculate the cash flows $C F_{t}$ for every period $t=1$ to $T$ and every price path $i=$ 1 to 10,000 . For reasons of simplicity and because it is not focus of this analysis, we assume that unobservable costs and benefits offset each other and hence $U C B_{t}=0$. Initially, we assume that $F_{c}, \varepsilon$ and $M$ were constant over time. In this analysis, we do not account for a Rebound Effect, and thus, set $M=1$. By discounting the future cash flows to present values with Eq. (6), we obtain $N P V_{i}$ for all price paths $i=1$ to 10,000 . The risk-free interest rate $r$ is fixed at 3\%. While obviously $r$ has an influence on the EE investment decision (Clinch and Healy 2001; Morrissey et al. 2013), it is not the focus of this analyses.

(Enter Table 2 here)

Table 2: Parameters for calculation of the $\mathrm{CF}_{t}$ and $\mathrm{NPV}_{\mathrm{i}}$.

In order to derive the objective probability of each of the 10,000 NPVs a Kernel Density Estimator (KDE) is applied to estimate the probability density function. ${ }^{11}$ By doing so, we derive all objective probabilities $p\left(\triangle N P V_{i}\right)$. These are the basis for further analyses of the difference between EUT and CPT, for evaluation of EE investments.

\subsection{CPT and EUT Analysis}

The aim of this study is to explain the EE gap by comparing an EE investment decision based on EUT and CPT. We computed the EUT and CPT values for different combinations of input parameters, as described above. For given input parameters, when both theories result in the same algebraic sign, the decision for an EE investment is the same and the EE gap cannot be explained. However, if the result for EUT is positive, and negative for CPT, the methods lead to different decisions. In this case, the EE gap can be explained by decision-making based on perceived values instead of expected utility.

11We applied the KDE with different kernels and bandwidths and achieved very similar results. 
In accordance with CPT, the natural reference-point of the EE investment is ' 0 ', because "the reference state usually corresponds to the decision maker's current position" (Tversky and Kahneman 1991, p.1046). We framed the EE investment decision in such a way that the maintenance measure (i.e., refurbishment of the existing house) would be carried out in any case. Hence, if no decision about the EE investment were made, no additional costs or benefits would occur. Thus, we set $\triangle N P V_{i}=$ $N P V_{i}$ for the following analysis. If the EE investment is carried out, the resulting NPV resembles exactly the gains or losses, as opposed to no additional investment. However, the reference-point "can also be influenced by aspirations, expectations, norms, and social comparison" (Tversky and Kahneman 1991, p.1046-47). To account for this fact and because of its major influence on the final decision, we discuss the influence of different reference points in Section 5.4.3.

In order to assess the impact of the various elements of CPT on the EE investment decision, we implement the different elements of CPT by means of a systematic approach similar to that used by Babcock (2015) and Dichtl and Drobetz (2011). This modular structure allows us to examine and separate the impact of different elements of CPT on the EE Gap.

(1) First, we just apply the value function in Eq. (2). However, we set the parameter for loss aversion to $\lambda=1$, and omit the weighting function of Eq. (3).

(2) Second, we use Eq. (2) and set $\lambda=2.25$. Thus, we also account for loss aversion.

(3) Finally, we account for all the elements of CPT as shown in Eq. (2)-(5).

We compare the results of the CPT analysis with EUT as described in Eq. (6). Thereby, we distinguish two utility functions $u()$ to consider different risk preferences:

(1) A linear utility function, representing a risk-neutral decision-maker: $u\left(\varphi_{i}\right)=\varphi_{i}$, and

(2) A power utility function that implies Constant Relative Risk Aversion (CRRA):

$$
u\left(\varphi_{i}\right)=\left\{\begin{array}{ll}
\frac{1}{1-\theta} \cdot\left(\varphi_{i}{ }^{1-\theta}-1\right) & \text { for } \theta \neq 1 \\
\ln \left(\varphi_{i}\right) & \text { for } \theta=1
\end{array},\right.
$$

For all levels of wealth $\varphi_{i}=\varphi_{0}+x_{i}>0$, where $\theta>0$ is the degree of relative risk aversion. For EUT, a utility function representing CRRA is applied to calibrate the degree of risk aversion of EUT. 
CPT exhibits CRRA for outcomes $x_{i}>0$. The Arrow-Pratt measure for relative risk aversion ${ }^{12}$ shows that, in the positive domain, the value function (i.e., $x^{\alpha}$ ) exhibits a relative-risk-aversion coefficient $\theta=1-\alpha$. Because total wealth is relevant for EUT, it is not a drawback that the utility function is only defined for the positive domain. It seems implausible that any negative outcome $x_{i}$ will exceed initial total wealth $\varphi_{o}$, because in the scenario assumed, the decision-maker is a houseowner, which implies a certain level of wealth.

However, applying a utility function exhibiting CRRA for EUT and CPT does not automatically make them comparable. Kahneman and Tversky (1979) estimated the value of $\alpha$ over modest stakes as well as in dependence of the reference point and the level of loss aversion. Thus, the resulting risk aversion coefficient $\theta=0.12$ may not be suitable to evaluate total wealth $\varphi_{i}$ for EUT. This becomes obvious when comparing $\theta=0.12$ with other empirical estimates. Often a much higher relative risk aversion coefficient (between ' 1 ' and ' 3 ') is found. For example, Layard et al. (2008) used a cross-sectional survey of subjective happiness and panel surveys between 1972 and 2005. They found a combined estimate of $\theta=1.26$, which is more than a tenfold increase in relative risk aversion compared to the value of Kahneman and Tversky. To account for this fact, in the following, we also compute EUTvalues based on higher $\theta$-values, while keeping the parameter $\alpha$ for CPT constant (implying a relative risk aversion coefficient of 0.12). We used Eq. (9) instead of $x^{\theta}$ because the latter function is restricted to $0<\theta<1$ for risk aversion.

\subsection{Main Simulation Results}

The results are based on a comparison of different parameter settings for the energy price simulation by Eq. (8), the NPV calculation by Eq. (6), and of the EUT and CPT calculations. The resulting decisions based on EUT and CPT are compared in a matrix depicting input combinations of investment costs $I_{0}$ and energy savings $\varepsilon$. Such a matrix is depicted in Figure 2 for different risk aversion parameters $\theta$. We apply this combination, because $I_{0}$ and $\varepsilon$ are the most important drivers for relevant decision criteria (Anderson and Newell 2004) and the $N P V_{i}$, as well. For example, Hope and

12The Arrow-Pratt measure for relative risk aversion can easily be calculated by: $-x \cdot u^{\prime \prime}(x) / u^{\prime}(x)$. 
Booth (2014) found that high up-front costs are the main reason why landlords do not execute EE investments. Given a fixed set of input parameters for price simulation etc., this setting allows comparison of rational decision-making and decision-making based on perceived values for different combinations of $I_{0}$ and $\varepsilon$. For the following analysis, combinations of $I_{0}$ ranging from 10,000-60,000€ (in increments of 1,000€) and $\varepsilon$ ranging from 5-80\% (in increments of 5\%) are examined. For every set of combinations of $I_{0}$ and $\varepsilon$ where EUT is positive but CPT is negative, the EE gap can be shown. Ceteris paribus, these are settings where the perceived value of CPT leads to a rejection of the EE investment. However, the analysis and conclusions are restricted to the intervals spanned by the incremental increase of investment costs (by 1,000€) and energy savings (by 5\%). Thus, in the worst case, while this analysis might identify an effect in the range 5,000-15,000€ it cannot be excluded that the actual change occurred in the range 4,001-15,999€. For the sake of clarity and computation time, however, we believe that this is an acceptable simplification. In this first attempt, it is not our objective to derive very detailed prices, but rather to demonstrate the general effect. Note, not all combinations must necessarily be technical and economically realistic combinations of investment costs $I_{0}$ and achievable energy savings $\varepsilon$. However, for the sake of completeness, and in order not to be reproached for arbitrariness of the chosen range of parameters, all the computed values are depicted. ${ }^{13}$

The analyses emanate from a baseline scenario and subsequently examine the effects of varying input parameters. These include the influence of increased volatility $\sigma$ of the domestic fuel oil price $P_{t}$ and the reference point $R P$. As described in Section 5.3, we apply a modular approach to CPT to examine the influence of different elements of CPT on the final EE investment decision. Moreover, for EUT, we distinguish between risk-neutrality and different levels of risk-aversion. Therefore, first, we introduce the baseline scenario and subsequently examine the influence of different parameters.

\section{(Enter Figure 3 here)}

Figure 3: Influence of risk aversion $\theta$ on the results as compared to risk-neutrality.

\footnotetext{
${ }^{13}$ However, this comes with the drawback that the effect of the EE gap may seem visually small.
} 


\subsubsection{Baseline Scenario}

Our baseline scenario starts from a risk-neutral EUT decision-maker and assumes a long-term trend of prices $\mu=4.8 \%$, a volatility of energy prices $\sigma=20 \%$, an initial energy price $P_{0}=0.085 € / \mathrm{kWh}$, an initial wealth $\varphi_{0}=300,000 €$, and a time horizon $T=25$ years. The input parameters are used to simulate price paths $i=1$ to 10,000 . Then, for every combination of $I_{o}$ and $\varepsilon$, the corresponding cash flows $C F_{t}$ are calculated with Eq. (7). The $N P V_{i}$ are obtained by discounting all $C F_{t}$ for all $t=1$ to $T$ for every price path $i=1$ to 10,000 with Eq. (6). Finally, the resulting distribution is used to calculate the risk-neutral EUT and CPT values. Figure 2 depicts the results for the described baseline scenario, given the input parameters specified above and the chosen combinations of $I_{0}$ and $\varepsilon$ respectively. Note that for reasons of clarity, we do not depict numerical utility values. Rather, an " $x$ " indicates that neither risk-neutral EUT, nor CPT favor the EE investment. Here, “*” indicates that both methods are positive toward an EE investment. Finally, "o" is a combination of $I_{0}$ and $\varepsilon$ where EUT is positive, but CPT is negative. Those combinations depict situations where CPT is able to explain the EE gap. The hatched combinations of $I_{o}$ and $\varepsilon$ indicate a change in the EUT decision as compared to the riskneutral case for the corresponding $\theta$.

First, we analyze the rational risk-neutral EUT decision-maker. This implies all "*” and "o" in Figure 2 are positive decisions toward the EE investment. As argued in Section 5.3, we also accounted for different degrees of risk-aversion by varying the coefficient of relative risk aversion $\theta$ of Eq. (9). Figure 2 compares how different levels of risk aversion $(\theta=0.12 ; 1.26 ; 3.0)$ influence the extent of the EE gap. For example, for $\theta=3.0, I_{0}=34,000 €$, and $\varepsilon=30 \%$, a risk-neutral EUT decisionmaker would favor the investment while a risk-averse decision-maker would decline it. However, by comparing the results in Figure 2, it becomes clear that for an initial wealth $\varphi_{o}=300,000 €$ the relative risk aversion factor $\theta$ has only minor influence. Decreasing the level of $\varphi_{o}$ only has a major impact when $\varphi_{o}<50,000 €$. In our setting, this is rather unrealistic because the decision-maker is the owner of the house under consideration, which in most cases should imply a higher level of initial wealth $\varphi_{o}$. 
Based on the value ranges for $I_{o}$ and $\varepsilon$ and all risk-aversions under consideration, all investments yielding an energy saving $\varepsilon<10 \%$ would be declined, while all investments yielding savings of more than $50 \%$ would be executed. Interestingly, when comparing two successive saving degrees, it becomes obvious that incremental savings of 5\% may not cost more than 5,000-6,000€ additional investment costs, to be accepted in both the risk-neutral and risk-aversion cases. For example, in the risk-neutral case, the last acceptable investment cost $I_{0}$, to achieve savings $\varepsilon$ of $30 \%$ is $34,000 €$, while it is $40,000 €$ for $35 \%$ savings. A risk-averse decision-maker requires a risk discount, so that the costs for incremental 5\% savings must decrease, as compared to risk-neutrality, to make an EE investment attractive. While this generally leads to a downward shift in acceptable investment costs $I_{0}$, incremental savings of 5\% might not cost more than 5,000-6,000€ additional investment costs for a risk-averse decision-maker.

Next, we look at the CPT decision-maker taking decisions based on perceived values. From this perspective, all "o" and "x" in Figure 2 depict decisions against the EE investment. First, we analyze the implementation of all elements of CPT according to Eq. (2) - (5) and compare it with that of a risk-neutral EUT decision-maker. Deviations of CPT compared to risk-neutral EUT again are marked with "o". Such deviations can be observed for saving degrees $\varepsilon$ between $10 \%$ and $65 \%$; thus, the EE gap can be clearly identified. The range of deviating values widens as the degree of saving increases. Thus, the higher the combination of saving degree $\varepsilon$ and investment costs $I_{0}$ under consideration, the higher the gap in the willingness of EUT and CPT decision-makers to invest. For example, for a saving degree of $45 \%$ a risk-neutral EUT decision-maker would be willing to invest up to $52,000 €$, whereas under CPT, this value would be considerably lower $(39,000 €)$. This is another way to describe the barrier of high investment costs as pointed out in Section 2.2. While only looking at the EUT does not allow for any conclusions concerning this issue, comparing these results with those for CPT, highlights that the higher the combination of investment costs and energy savings, the more pronounced the EE gap.

Within the CPT framework, this fact can be explained with the increased number of possible negative NPVs. In spite of higher achievable energy savings $\varepsilon$ through higher investment costs $I_{0}$, because of 
the stochasticity of energy prices, it is less likely that accrued present value energy savings would exceed investment costs. With prevailing loss aversion such negative outcomes are valued much higher, and thus result in negative decisions. The influence of loss aversion becomes obvious when implementing only the value function of Eq. (2), while omitting loss aversion $(l=1)$ and probability weighting. Then, the extent to which CPT explains the EE gap is negligible. However, when setting $l=2.25$, but still omitting probability weighting, deviations from EUT evolve. Yet, adding probability weighting does not considerably change the results. This might be explained by a probability distribution where both extremely high and extremely low NPVs, both with low probability, offset each other. Figure 3 shows the impact of the different elements of CPT compared to risk-neutral EUT. Finally, we can conclude that CPT can explain the EE gap. Thereby, loss aversion has a major influence, while probability weighting and the value function (with $l=1$ ), are rather negligible.

\section{(Enter Figure 4 here)}

Figure 4: Modular implementation of the CPT.

So far, the comparison is hampered by the fact that a risk-neutral EUT decision-maker does not reflect commonly observed risk-preferences. Risk-neutrality implies that one decides on expected value and that decisions are not affected by the degree of risk in the set of NPVs. However, as we have argued above, the influence of the risk aversion parameter is rather negligible. Only for risk aversion as high as $\theta=3$, we observe a considerable change in decisions on the EE investment, as indicated by the hatched combinations in Figure 3. Considering this degree of risk aversion for many saving degrees $\varepsilon$ between 20\% and 50\%, we observe a decreasing number of deviating EUT and CPT decisions, as compared to a risk-neutral EUT decision maker. For example, for $\varepsilon=45 \%$, the range of deviating decisions from 40,000-58,000€ for risk-neutral EUT decreases to the range of 40,000-49,000€ for a risk-averse EUT decision-maker. Thus, one could conclude that the EE gap could be fully explained by simply adjusting the degree of risk aversion. However, when the coefficient of risk aversion $\theta$ is increased even more, it leads to unrealistic results. While the EE gap almost vanishes for small investment costs $I_{0}$, for higher $I_{0}$, even otherwise very profitable combinations of $I_{0}$ and $\varepsilon$ would not 
be executed. This might be explained by the theorem of Rabin (2000). The theorem shows that when risk aversion is modeled with a concave utility function in EUT, then even low risk aversion over modest stakes might lead to unrealistic risk aversion over larger stakes. EUT is therefore not very helpful to explain risk attitudes that allow for considerable small-scale risk aversion, and for plausible large-scale risk aversion.

\subsubsection{Influence of Volatility}

One of the most cited reasons for the EE gap is the high risk regarding future energy prices (Diederen et al. 2003; Greene 2011; Hasset and Metcalf 1993). The price path of energy prices is not predictable and, thus, a considerable source of risk for EE investment. High volatility of energy prices also increases the risk of low energy prices and, thus, achievable future savings might decrease. This would result in a higher number of negative NPVs, which are penalized by loss aversion in CPT. So far, the main parameter covering risk, the volatility $\sigma$, has been set to $\sigma=20 \%$. In the following, by changing the volatility parameter to $\sigma=30 \%$ and $\sigma=10 \%$, the randomness around the long-term trend $\mu$ will be increased or decreased, respectively.

Given a long-term trend $\mu=4.8 \%$, a time horizon $T=25$, an initial wealth $\varphi_{o}=300,000 €$ and a relative risk aversion $\theta=0.12$, we analyze the influence of price volatility $\sigma$ on the extent of the EE gap. Figure 4 depicts results for all volatilities under consideration in the matrix of investment costs $I_{0}$ and energy savings $\varepsilon$ introduced earlier. Again, "o" depicts a combination of $I_{0}$ and $\varepsilon$ where EUT is positive but CPT is negative and, thus, the EE gap can be explained. The results indicate that, with growing volatility, the size of the EE gap increases. For example, for energy savings of $\varepsilon=45 \%$, the EE gap can be explained by CPT for $\sigma=10 \%$ in a range of 7,000€ ( $I_{0}$ from $\left.46,000-53,000 €\right)$, for $\sigma=20 \%$ in a range of $12,000 €\left(I_{0}\right.$ from $\left.40,000-52,000 €\right)$, and for $\sigma=30 \%$ in a range of $14,000 €$ ( $I_{0}$ from 36,000-50,000€). This leads to another observation: with growing $\sigma$ not only does the size of the EE gap increase, but it also shifts to lower ranges of $I_{0}$ for any given $\varepsilon$. On the one hand, this means that with increasing $\sigma$ the EUT decision-maker would reduce the amount of investment costs $I_{0}$ he is willing to pay for a given $\varepsilon$. This effect becomes more pronounced the higher the $\varepsilon$. On the 
other hand, in a similar way, the CPT decision-maker is also less willing to pay higher $I_{0}$ for desired $\varepsilon$. Thereby, this effect is even more pronounced than for the EUT decision-maker. We conclude that rising energy price volatility $\sigma$ reduces the amount of $I_{0}$ the EUT and CPT decision-makers are willing to pay for a given $\varepsilon$. Because this effect is more pronounced for CPT, a higher volatility leads to an increase, and a shift towards lower investment costs, of the EE gap. Thus, uncertainty as the most often stated reason for the EE gap can be explained and quantified using CPT.

(Enter Figure 5 here)

Figure 5: Influence of volatility $\sigma$ on the extent of the EE gap.

\subsubsection{Influence of the Reference Point}

In Section 5.3, we defined the reference-point $R P=0$. Thus, $\triangle N P V_{i}=N P V_{i}+R P=N P V_{i}$. It is often unclear how to choose the $R P$, as Kahneman and Tversky did not focus on a detailed description on how to determine the origin of the value function. Often, as in our case, the reference-point corresponds to the status quo and therefore, $R P=0$. However, because of the asymmetry of gains and losses divided by the reference-point, its determination has a major influence on choice. Kahneman and Tversky (1979, p.274) stated that "the location of the reference point, and the consequent coding of outcomes as gains or losses, can be affected by the formulation of the offered prospects, and by the expectations of the decision maker". In the following, we analyze situations where gains and losses are not coded relative to the status quo, but relative to expected consumption, expected asset positions, or aspiration levels (Kőszegi and Rabin 2006; Tversky and Kahneman 1991). When the NPV relative to the reference-point RP is defined as $\triangle N P V_{i}=N P V_{i}+R P$, then from Eq. (6) it follows that $\triangle N P V_{i}=$ $-I_{0}+\sum_{t=1}^{T} C F_{t} \cdot(1+r)^{-t}+R P$. Thus, from a computational perspective, a variation of $R P$ corresponds to increasing or decreasing investment costs $I_{0}$. When the reference-point is framed as a loss, then $R P<0$, which results in decreasing $I_{0}$. For instance, the decision may be framed in a way that, when not conducting the EE investment, unrealized future energy savings are perceived as a loss. On the other hand, when the reference point is framed as an expected gain, then $R P>0$, which results in increasing $I_{0}$. For example, the decision-maker may expect a minimum return on investment costs of the risk-free interest rate. Then, only returns above that threshold would be perceived as a gain. As 
change of the reference-point can be shown by adjusting the investment costs $I_{0}$, its effects on decision-making can easily be shown in Figure 2. Consider a reference-point $R P=-5,000 €$ and $\varepsilon=$ $15 \%$, then the former CPT decision for $I_{0}=17,000 €$ changes to the CPT decision depicted at $I_{0}=$ $17,000 €-5,000 €=12,000 €$ from not investing in the former, to investing in the latter. Obviously, it is the other way round when $R P>0$. It follows that when RP is framed as a gain, the EE gap is increased, and it is decreased for a RP framed as a loss. This has already been mentioned for EE and related literature (e.g., Dinner et al. 2011; Goldstein et al. 2008; Gerarden et al. 2015; Hartman et al. 1991), but to the best of our knowledge, we are the first to depict this effect in a quantitative model.

\section{Conclusions and Policy Implications}

Recent environmental policy has included announcements of ambitious targets in achieving EE in the years ahead. At the same time, it is often asserted that many cost-effective EE investments are not executed. One explanation for this well-known EE gap involves behavioral barriers. In this study, we used CPT, put forward by Tversky and Kahneman (1992), to explain the decision-making of individuals with regards to EE investments. Specifically, we illustrated how the extent of the EE gap is influenced by behavioral biases such as loss aversion, probability weighting, and framing, as compared to the rational decision-maker assumed within EUT. We find compelling evidence for the explanatory power of CPT toward the EE gap and additional valuable insights that may guide the design of effective public policy interventions.

First, our analysis shows that the higher the investment costs, the greater the size of the EE gap. This quantitatively explains the commonly mentioned barrier of high upfront costs. Second, the risk as depicted by the volatility of energy prices also increases the extent of the EE gap. In line with Rabin (2000), we find evidence that CPT is better able to describe risk-aversion over higher stakes than EUT. Third, by implementing the modular elements of CPT, we can conclude that loss aversion is the major driver of the EE gap. Our results indicate that other elements of CPT such as probability weighting, have a rather negligible influence. As an exception, however, we find the determination of the reference-point to be very important. Depending on how the EE investment decision is framed, or perceived by the decision-maker, the EE gap might vanish or be amplified. Generally, our results 
quantitatively back the predictions of related qualitative research about the impact of CPT on the EE gap (e.g., Frederiks et al. 2015; Gillingham and Palmer 2014; Pollit and Shaorshadze 2013; Shogren and Taylor 2008; Wilson and Dowlabati 2007).

Our results lead us to conclude that CPT provides insights valuable for environmental policymaking. While the standard market failure motivation for government involvement is based on creation of markets, behavioral barriers refer to the individual decision-maker. However, behavioral biases are systematic and pervasive, so we believe government interventions are justified beyond market failure. In otherwise perfect markets, when individuals systematically deviate from optimal decision-making, consumer-focused government intervention may "nudge" individuals toward the right direction without limiting the freedom of choice. This form of intervention has been called libertarian paternalism (see Thaler and Sunstein 2003).

While the effects of behavioral anomalies on investment decisions in EE have mostly been a "black box" up to now, we provide a first means to explicitly calculate their quantitative impact. Based on a complete implementation of the CPT framework we are able to perform a thorough analysis and quantification of different behavioral biases. In particular, we are able to determine which behavioral biases have the strongest explanation power toward the existence of the EE gap. These results might help to enlighten the "black box" concerning the effects of behavioral anomalies, and therefore, make them effectively correctible by environmental policy measures. Government policies could be based on behavioral insights either by directly addressing the consumer or indirectly by enabling companies to adjust their operations accordingly.

For example, direct policies include targeted and quantitatively backed public awareness campaigns. They can foster EE investments by addressing the most relevant behavioral barriers, such as loss aversion and framing as suggested by Nair et al. (2010). Same holds true for intelligent financial incentives by government programs for EE that directly address behavioral barriers of individual consumers. 
On the other hand, indirect policies are mainly related to the support of private companies in order to enable them to offer solutions which address relevant behavioral biases. For example, energy savings insurance, or guarantees, could be promoted to reduce the probability of negative NPVs counteracting loss aversion while presenting an interesting business case for insurance companies (e.g., Mills 2003). Also Energy Service Companies may be encouraged to use the CPT framework to align their business model and the pricing of contracts to actual human behavior. Especially energy performance contracting for private consumers could be backed by quantitative insights about human behavior.

Despite these findings, our paper is also associated with some limitations. (1) Our approach relies on several reasonable assumptions about costs and benefits. These influence the cash flow structure and thus may alter decision-making. Therefore, our analysis could be expanded by adding unobservable costs and benefits, changing the stochastic price process or accounting for the rebound effect. (2) We only focused on behavioral barriers to EE investments implemented in CPT, but neglected possible market failures and other barriers such as time inconsistent preferences. For purposeful policymaking, interrelations between different barriers have to be accounted for and treated in a holistic manner (see Chai and Yeo 2012). (3) A meaningful comparison of the extent of the EE gap to empirical evidence is hardly feasible within the limits of this paper. For example, most of the evidence on the EE gap is based on implicit discount rates derived on basis of the willingness to pay for an EE investment given future monetary returns. However, our approach is based on utility values that cannot be compared to monetary values in a meaningful way. Further research could focus on this issue. (4) We did not examine the parameters for CPT empirically, but relied on the original specifications by Tversky and Kahneman (1992). However, these parameters could be verified and examined empirically applying randomized controlled trials or quasi-experimental methods in the context of EE investment decisions. (5) Our conclusions were drawn from a realistic but only exemplary application. The introduced approach and its conclusions should be verified by applying it to other scenarios as well.

Despite these limitations, we developed a general and widely applicable approach to evaluate EE investment decisions under CPT. In particular, we showed that behavioral barriers could explain the EE gap. Additionally, CPT provides insights into many of the commonly cited barriers to EE 
investments. Thus, we created the basis to develop further solutions to quantify behavioral barriers causing the EE gap. By providing insights into the decision-making of an individual EE investor, this paper can support policy makers in creating incentives that accelerate the adoption of EE technologies. 


\section{References}

Abrahamse, W., Steg, L., Vlek, Ch., Rothengatter, T., 2005. A review of intervention studies aimed at household energy conservation, in: J. of Environ. Psycho. 25, 273-291.

Ådahl, A., Harvey, S., 2007. Energy efficiency investments in Kraft pulp mills given uncertain climate policy, in: Int. J. of Energy Res. 31, 486-505.

Allcott, H., Greenstone, M., 2012. Is There an Energy Efficiency Gap? In: J. of Econ. Perspect. 26, 3-28.

Alcott, H., Rogers, T., 2014. The Short-Run and Long-Run Effects of Behavioral Interventions: Experimental Evidence from Energy Conservation, in: The Am. Econ. Rev. 104, 10, 3003-3037.

Amstalden, R. W., Kost, M., Nathani, C., Imboden, D. M., 2007. Economic potential of energy-efficient retrofitting in the Swiss residential building sector: The effects of policy instruments and energy price expectations, in: Energy Policy 35, 1819-1829.

Anderson, S. T., Newell, R. G., 2004. Information programs for technology adoption: the case of energyefficiency audits, in: Resour. and Energy Econ. 26, 27-50.

Ansar, J., Sparks, R., 2009. The experience curve, option value, and the energy paradox, in: Energy Policy 37, $1012-1020$.

Babcock, B. A., 2015. Using Cumulative Prospect Theory to Explain Anomalous Crop Insurance Coverage Choice, in: Am. J. of Agric. Econ. 97, 1-14.

Bamberg, G., Dorleitner, G., Krapp, M., 2006. Unternehmensbewertung unter Unsicherheit: Zur entscheidungstheoretischen Fundierung der Risikoanalyse, in: Zeitschr. für Betriebsw. 76, 3 ,287-307.

Barberis, N. C., 2013. Thirty Years of Prospect Theory in Economics: A Review and Assessment, in: J. of Econ. Perspect. 27, 173-196.

Barr, S., Gilg, A. W., Ford, N., 2005. The household energy gap: examining the divide between habitual- and purchase-related conservation behaviours, in: Energy Policy 33, 1425-1444.

Benartzi, S., Thaler, R. H., 1995. Myopic Loss Aversion and the Equity Premium Puzzle, in: Quart. J. of Econ. 110, 73-92. 
Blumstein, C., Krieg, B., Schipper, L., York, C., 1980. Overcoming social and institutional barriers to energy conservation, in: Energy 5, 355-371.

Brown, M. A., 2001. Market failures and barriers as a basis for clean energy policies. Scenarios for a clean energy future, in: Energy Policy 29, 1197-1207.

Brown, M. A., Levine, M. D., Romm, J. P., Rosenfeld, A. H., Koomey, Jonathan G., 1998. Engineering-

Economic Studies of Energy Technologies to reduce Greenhouse Gas Emissions: Opportunities and Challenges, in: Annu. Rev. of Energy and the Environ. 23, 287-385.

Camerer, C. F., Ho, T.-H., 1994. Violations of the betweenness axiom and nonlinearity in probability, in: J. of Risk Uncertain. 8, 167-196.

Camerer, C., Loewenstein, G., Rabin, M., 2004. Advances in behavioral economics. Russel Sage Foundation, Princeton University Press, Princeton, NJ, Oxford, UK.

Chai, K.-H., Yeo, C., 2012. Overcoming energy efficiency barriers through systems approach-A conceptual framework, in: Energy Policy 46, 460-472.

Clinch, P. J., Healy, J. D., 2001. Cost-benefit analysis of domestic energy efficiency, in: Energy Policy 29, $113-$ 124.

Coltrane, S., Archer, D., Aronson, E., 1986. The social-psychological foundations of successful energy conservation programmes, in: Energy Policy 14, 133-148.

De Groot, H. L. F., Verhoef, E. T., Nijkamp, P., 2001. Energy saving by firms: decision-making, barriers and policies, in: Energy Econ. 23, 717-740.

DeCanio, S. J., 1993. Barriers within firms to energy-efficient investments, in: Energy Policy 21, $906-914$.

DeCanio, S. J., Watkins, W. E., 1998. Investment In Energy Efficiency: Do The Characteristics Of Firms Matter? In: Rev. of Econ. Stat. 80, 95-107.

DellaVigna, S., 2009. Psychology and Economics: Evidence from the Field, in: J. of Econ. Lit. 47, 315-372.

DENA (Deutsche Energie-Agentur), 2012. Der dena-Gebäudereport 2012: Statistiken und Analysen zur Energieeffizienz im Gebäudebestand. Deutsche Energie-Agentur, Berlin, Germany. 
Department of Energy, 2015. President Obama Announces More Than a Billion Dollars in Energy Department Initiatives to Advance Innovative Clean Energy Technologies. http://www.energy.gov/articles/president-obamaannounces-more-billion-dollars-energy-department-initiatives-advance (accessed: 06.05.2016).

Dichtl, H., Drobetz, W., 2011. Portfolio insurance and prospect theory investors: Popularity and optimal design of capital protected financial products, in: J. Bank. Finance 35, 1683-1697.

Diederen, P., van Tongeren, F., van der Veen, H., 2003. Returns on Investments in Energy-saving Technologies Under Energy Price Uncertainty in Dutch Greenhouse Horticulture, in: Environ. Resour. Econ. 24, 379-394.

Dinner, I., Johnson, E. J., Goldstein, D. G., Liu, K., 2011. Partitioning Default Effects: Why People Choose Not to Choose, in: J. Exp. Psychol. 17, 332-341.

Dubin, J. A., McFadden, D. L., 1984. An Econometric Analysis of Residential Electric Appliance Holdings and Consumption, in: Econ. 52, 345-362.

Enseling, A., Hinz, E., Vaché, M., 2013. Akteursbezogene Wirtschaftlichkeitsberechnung von Energieeffizienzmaßnahmen im Bestand - Berechnung mit dem Vollständigen Finanzplan. Darmstadt, Germany: Institut Wohnen und Umwelt.

European Commission, 2011. Energy Roadmap 2050. European Commission, 2011. http://ec.europa.eu/ (accessed: 06.05.2016).

Fennema, H., Wakker, P., 1997. Original and cumulative prospect theory: a discussion of empirical differences, in: J. Behav. Decis. Mak. 10, 53-64.

Fowlie, M., Greenstone, M., Wolfram, C., 2015. Are the non-monetary costs of energy efficiency investments large? Understanding low take-up of a free energy efficiency program, in: The Am. Econ. Rev. 105, 5, 201-204.

Frederick, S., Loewenstein, G., O’Donoghue, T., 2002. Time discounting and time preference: A critical review, in: J. of Econ. Lit. 40, 351-401.

Frederiks, E., Stenner, K., Hobman, E. V., 2015. Household energy use: Applying behavioural economics to understand consumer decision-making and behaviour, in: Renewable and Sustain. Energy Rev. 41, 1385-1394.

Gardner, G. T., Stern, P. C., 2002. Environmental problems and human behavior. Second Edition, Person Custom Publishing, Boston. 
Gaspar, R., Antunes, D., 2011. Energy efficiency and appliance purchases in Europe: Consumer profiles and choice determinants, in: Energy Policy 39, 7335-7346.

Gately, D., 1980. Individual Discount Rates and the Purchase and Utilization of Energy-Using Durables:

Comment, in: Bell J. Econ. 11, 373-374.

Gates, R. W., 1983. Investing in energy conservation: Are homeowners passing up high yields? In: Energy Policy 11, 63-71.

Gerarden, T., Newell, R. G., Stavins, R. N., 2015. Deconstructing the Energy-Efficiency Gap: Conceptual Frameworks and Evidence, in: Am. Econ. Rev. 105, 183-186.

Gillingham, K., Newell, R. G., Palmer, K., 2009. Energy Efficiency Economics and Policy, in: Annu. Rev. Resour. Econ. 1, 597-620.

Gillingham, K., Palmer, K., 2014. Bridging the energy efficiency gap: Policy insights from economic theory and empirical evidence, in: Rev. of Environ. Econ. and Policy, 8, 1, 18-38.

Gintis, H., 2000. Beyond Homo economicus: evidence from experimental economics, in: Ecol. Econ. 35, 311322.

De Giorgi, E., Hens, T., 2006. Making prospect theory fit for finance, in: Financial Mark. Portfolio Manag. 20, $339-360$.

Goldstein, N. J., Cialdini, R. B., Griskevicius, Vladas, 2008. A Room with a Viewpoint: Using Social Norms to Motivate Environmental Conservation in Hotels, in: J. Consumer Res. 35, 472-482.

Gonzalez, R., Wu, G., 1999. On the Shape of the Probability Weighting Function, in: Cogn. Psychol. 38, 129166.

Gowdy, J. M., 2008. Behavioral economics and climate change policy, in: J. Econ. Behav. \& Organ. 68, 632644.

Granade, H. C., Creyts, J., Derkach, A., Farese, P., Nyquist, S., Ostrowski, K., 2009. Unlocking energy efficiency in the U.S. economy. McKinsey \& Company, United States.

Greene, D. L., 2011. Uncertainty, loss aversion, and markets for energy efficiency. Special Issue on The Economics of Technologies to Combat Global Warming, in: Energy Econ. 33, 608-616. 
Hartman, R. S., Doane, M. J., Woo, C.-K., 1991. Consumer Rationality and the Status Quo, in: Q. J. Econ. 106, $141-162$.

Hassett, K. A., Metcalf, G. E., 1993. Energy conservation investment: Do consumers discount the future correctly? In: Energy Policy 21, 710-716.

Hausman, J. A., 1979. Individual Discount Rates and the Purchase and Utilization of Energy-Using Durables, in: Bell J. Econ. 10, 33-54.

Hirst, E., 1986. Actual energy savings after retrofit: Electrically heated homes in the Pacific Northwest, in: Energy 11, 299-308.

Hope, A. J., Booth, A., 2014. Attitudes and behaviours of private sector landlords towards the energy efficiency of tenanted homes, in: Energy Policy 75, 369-378.

Howarth, R. B., Andersson, Bo, 1993. Market barriers to energy efficiency, in: Energy Econ. 15, $262-272$.

Ingersoll, J., 2008. Non-Monotonicity of the Tversky-Kahneman Probability-Weighting Function: A Cautionary Note, in: Eur. Financial Manag. 14, 385-390.

Jaffe, A. B., Newell, R. G., Stavins, R. N., 2004. Economics of Energy Efficiency, in: Cutler, J. C. (Ed.), Encycl. of Energy. Elsevier, New York, U.S., pp. 79-90.

Jaffe, A. B., Stavins, R. N., 1994a. The energy-efficiency gap: What does it mean? Markets for energy efficiency, in: Energy Policy 22, 804-810.

Jaffe, A. B., Stavins, R. N., 1994b. The energy paradox and the diffusion of conservation technology, in: Resour Energy Econ. 16, 91-122.

Jakob, M., 2006. Marginal costs and co-benefits of energy efficiency investments: The case of the Swiss residential sector. Reshaping Markets for the Benefit of Energy Saving Reshaping Markets for the Benefit of Energy Saving, in: Energy Policy 34, 172-187.

Johnson, B. E., 1994. Modeling energy technology choices: Which investment analysis tools are appropriate? Markets for energy efficiency, in: Energy Policy 22, 877-883.

Kahneman, D., Tversky, A., 1979. Prospect Theory: An Analysis of Decision under Risk, in: Econ. 47, $263-291$.

Kempton, W., Montgomery, L., 1982. Folk quantification of energy, in: Energy 7, 817-827. 
Knetsch, J. L., 1997. Evaluation and environmental policies. Recent behavioural findings and further implications, in: Dragun, A., Jakobsson, K. (Eds.), Sustainability and Global Environmental Policy: New Perspectives. Edward Elgar Publishing, Cheltenham, UK, pp. 193-212.

Koomey, J. G., Sanstad, A. H., 1994. Technical evidence for assessing the performance of markets affecting energy efficiency. Markets for energy efficiency, in: Energy Policy 22, 826-832.

Koomey, J. G., Sanstad, A. H., Shown, L. J., 1996. Energy-efficient lighting: Market Data, Market Imperfections, and Policy Success, in: Contemp. Econ. Policy 14, 98-111.

Kőszegi, B., Rabin, M., 2006. A Model of Reference-Dependent Preferences, in: Q. J. Econ. 121, 1133-1165.

Laibson, D., 1997. Golden eggs and hyperbolic discounting, in: The Quart. J. of Econ. 112, 2, 443-478.

Lattimore, P. K., Baker, J. R., Witte, Ann D., 1992. The influence of probability on risky choice: A parametric examination, in: J. Econ. Behav. Organ. 17, 377-400.

Layard, R., Mayraz, G., Nickell, S., 2008. The marginal utility of income. Special Issue: Happiness and Public Economics, in: J. Public Econ. 92, 1846-1857.

Linares, P., Labandeira, X., 2010. Energy efficiency. Economics and policy, in: J. Econ. Surv. 24, 573-592.

Loewenstein, G., Thaler, R. H., 1989. Anomalies: intertemporal choice, in: J. Econ. Perspect. 65, 3, 181-193.

Lovins, A. B., 1992. Energy-efficient buildings. Institutional barriers and opportunities. Boulder, CO: E Source.

Masini, A., Menichetti, E., 2012. The impact of behavioural factors in the renewable energy investment decision making process: Conceptual framework and empirical findings. Strategic Choices for Renewable Energy Investment, in: Energy Policy 40, 28-38.

Mayer, P. C., 1995. Electricity Conservation: Consumer Rationality Versus Prospect Theory, in: Contemp. Econ. Policy 13, 109-118.

Meier, A. K., Whittier, Jack, 1983. Consumer discount rates implied by purchases of energy-efficient refrigerators, in: Energy 8, 957-962.

Metcalf, G. E., 1994. Markets for energy efficiency Economics and rational conservation policy, in: Energy Policy 22, 819-825. 
Mills, E., 2003. The insurance and risk management industries: new players in the delivery of energy-efficient and renewable energy products and services, in: Energy Policy 31, 1257-1272.

Min, J., Azevedo, I. L., Michalek, J., de Bruin, W. B., 2014. Labeling energy cost on light bulbs lowers implicit discount rates, in: Ecol. Econ. 97, 42-50.

Morrissey, J., Meyrick, B., Sivaraman, D., Horne, R. E., Berry, M., 2013. Cost-benefit assessment of energy efficiency investments: Accounting for future resources, savings and risks in the Australian residential sector. Decades of Diesel, in: Energy Policy 54, 148-159.

Nair, G., Gustavsson, L., Mahapatra, K., 2010. Factors influencing energy efficiency investments in existing Swedish residential buildings, in: Energy Policy 38, 2956-2963.

Pollitt, M. G., Shaorshadze, I., 2013. The role of behavioural economics in energy and climate policy, in: Fouquet, R. (Ed.), Handbook on Energy and Climate Change. Edward Elgar Publishing, Cheltenham, UK, pp. $523-546$.

Rabin, M., 2000. Risk Aversion and Expected-utility Theory: A Calibration Theorem, in: Econ. 68, 1281-1292.

Rickard, S., Hardy, B., Von Neida, B., Mihlmester, P., 1998. The investment risk in whole building energyefficiency upgrade projects. Proceedings of the American Council for an Energy-Efficient Economy 1998 Summer Study on Energy Effciency in Buildings, Vol. 4, Washington, DC, 307-318.

Rosenfeld, A. H., Atkinson, C., Koomey, J., Meier, A. K., Mowris, R. J., Price, L., 1993. Conserved energy supply cures for U.S. buildings, in: Contemp. Econ. Policy 11, 45-68.

Ruderman, H., Levine, M. D., MacMahon, J. E., 1987. The behavior of the market for energy efficiency in residential appliances including heating and cooling equipment, in: Energy J. 8, 101-124.

Shaw, D. W., Woodward, R. T., 2008. Why environmental and resource economists should care about nonexpected utility models, in: Resour. Energy Econ. 30, 66-89.

Shimizu, K., 2007. Prospect Theory, Behavioral Theory, and the Threat-Rigidity Thesis: Combinative Effects on Organizational Decisions to Divest Formerly Acquired Units, in: Acad. Manag. J. 50, 1495-1514.

Shogren, J. F., Taylor, L. O., 2008. On Behavioral-Environmental Economics, in: Rev. Environ. Econ. Policy 2, $26-44$.

Stern, P. C., 2011. Contributions of psychology to limiting climate change, in: Am. Psychol. 66, 303. 
Stern, P. C., Aronson, E., 1984. Energy use. The human dimension. W.H. Freeman, New York.

Sutherland, R. J., 1991. Market Barriers to Energy-Efficiency Investments, in: Energy J. 12, 15-34.

Sütterlin, B., Brunner, T. A., Siegrist, M., 2011. Who puts the most energy into energy conservation? A segmentation of energy consumers based on energy-related behavioral characteristics, in: Energy Policy, 39, 8137-8152.

Thaler, R. H., 1981. Some empirical evidence on dynamic inconsistency, in: Econ. Letters 8, 201-207.

Thaler, R. H., Sunstein, C. R., 2003. Libertarian Paternalism, in: Am. Econ. Rev. 93, 175-179.

Thompson, P. B., 1997. Evaluating energy efficiency investments: accounting for risk in the discounting process, in: Energy Policy 25, 989-996.

Tversky, A., Kahneman, D., 1991. Loss Aversion in Riskless Choice: A Reference-Dependent Model, in: Q. J. Econ. 106, 1039-1061.

Tversky, A., Kahneman, D., 1992. Advances in prospect theory: Cumulative representation of uncertainty, in: $J$. Risk Uncertain. 5, 297-323.

van Soest, D. P., Bulte, E. H., 2001. Does the Energy-Efficiency Paradox Exist? Technological Progress and Uncertainty, in: Environ. Resour. Econ. 18, 101-112.

Vine, E., Hamrin, J., Eyre, N., Crossley, D., Maloney, M., Watt, G., 2003. Public policy analysis of energy efficiency and load management in changing electricity businesses, in: Energy Policy 31, 405-430.

Wakker, P., 1989. Transforming Probabilities without Violating Stochastic Dominance, in: Roskam, E. (Ed.), Mathematical Psychology in Progress. Springer, Berlin, Germany, pp. 29-47.

Weber, L., 1997. Some reflections on barriers to the efficient use of energy, in: Energy Policy 25, 833-835.

Wen, Y.-F., 2010. Capital investment decision, corporate governance, and prospect theory, in: Procedia - Soc. Behav. Sci. 5, 116-126.

Wilson, C., Dowlatabadi, H., 2007. Models of Decision Making and Residential Energy Use, in: Annu. Rev. Environ. Resour. 32, 169-203. 